\title{
Factors Associated with Low Back Pain Among Nurses in Critical Care Units, Hospital Universiti Sains Malaysia
}

\author{
Chan Siok Gim* \\ Open University Malaysia, Kelantan, Malaysia
}

Received: December 12, 2017; Published: December 20, 2017

*Corresponding author: Chan Siok Gim, Open University Malaysia, Kelantan, Malaysia

\begin{abstract}
Nursing is a high risk group profession with prevalence of low back pain LBP. Nursing literature shows that efforts have been done to try and reduce the problem of work-related low back pain while moving and handling, by training and the provision of handling aids. This study aims to determine work-related low back pain among nurses in critical care units and factors influencing low back pain. A quantitative, crosssectional and survey design was used to conduct the study in critical care units in Hospital Universiti Sains Malaysia. A total of 110 (81.5\%) nurses participated in the study. Data was collected using self-administered questionnaires. Data was analysed using the SPSS version 18.0. Descriptive statistics were employed to summarize the demographic data of the study sample while non-parametric tests were used to analyze the nursing profile and factors associated with LBP. Findings of this study broadly confirm high levels of LBP among nurses with $16.4 \%$ pre nursing LBP and $68.2 \%$ since nursing LBP. Working experience in current ward, nursing experience, age and frequent standing are positively associated with LBP. The main route to prevention of LBP among nurses is improved manual handling technique while transferring patient in the wards.
\end{abstract}

Keywords: Nursing; Low Back Pain; Employment Profile; Personal Factorsp; Work Related Factors

Abbreviations: LBP: Low Back Pain; HUSM: Hospital Universiti Sains Malaysia; CCUs: critical care units; HRPZ: Hospital Raja Perempuan Zainal

\section{Introduction}

Low back pain (LBP) is one of the most serious health problem of tremendous medical and socioeconomic dimension and a major cause of disability. Low back pain can defined a pain localized between the $12^{\text {th }}$ rib and the interior gluteal folds, with or without leg pain. Nurses are known to be a high risk group for occupational low back pain $[1,2]$. Direct care nursing personnel around the world report high numbers of work-related musculoskeletal disorders. The impact of LBP for nurses includes time off work, increased risk of becoming chronic, as well as associated personal and economic costs [3]. Nurses who suffer from chronic back pain will have an impact on them while standing up from sitting and lifting the patients. For direct care nursing staff, manual handling of patients such as moving or repositioning a patient using their own body strength is the major cause of these injuries [3]. Indeed, $80 \%$ of the general active population suffers from LBP at least temporarily [4]. His study with 350 employees shows that common LBP is the first reason of affections limiting professional activities before 45 years and the third after respiratory and traumatic affections between 45 and 65 years. In western countries, many of studies researched on back pain as a common problem for nurses [5]. Statistics in Hospital Universiti Sains Malaysia (HUSM) show that number of patients with back pain including nurses in year 2007 was 37, in year 2008 was 31 and in year 2009 were 26 as in physiotherapy records. Thus, this study intends to identify factors associated with back pain among nurses in critical care unit at HUSM, Kubang Kerian, Kelantan. The general objectives of this study was to identify employment profile of the nursing profession that were associated with LBP; determine personal factors of nurses related to LBP and explore work related factors associated with LBP.

\section{Materials and Method}

A cross-sectional study design was used to examine factors that are associated with LBP among nurses using a self-administered questionnaire conducted among nurses working in critical care units (CCUs) in HUSM. The questionnaire used consists of three sections; Section A is on the demographic data consisting of 10 items and Part B consists of 25 items on nursing and LBP and Part $\mathrm{C}$ is on treatment options consisting of 10 items. The questionnaire items were adopted from Branney and Newell [1]. The English version of the questionnaire was translated into Bahasa Malaysia and back translated to English by two independent professional translators. After it was back translated, it was found to be similar to 
the original one. To ensure the validity of items in the questionnaire, a pilot study was done at Hospital Raja Perempuan Zainal II (HRPZ II). A total of 30 nurses participated in this pilot study with informed consent. The questionnaire took approximately 15 to 20minutes to complete. Cronbach's alpha obtained for this pilot study was 0.75 which indicates a reasonable internal consistency. This study was approved by the Human Research Ethics Committee USM, USMKK/PPP/JEPeM [246.4.(1.4)] and Jawatankuasa Etika \& Penyelidikan Perubatan Kementerian Kesihatan Malaysia, (2) dlm KKM/NIHSEC/08/0804/P12-41.

\section{Results}

The total population of nurses working in all five wards adds up to 180; 8 Selatan consists of 31 nurses, ICU 51 nurses, Kristal 24 nurses, CCU 25 nurses, and HDU 49 nurses. However, only 110 (81.5\%) participated in this study in February 2012. Majority of the participants were female nurse 85 (77.3\%) while $25(22.7 \%)$ participants were male nurses. The majority of the participants were Malays 101 (91.8\%), there were six Chinese (5.5\%) and three Indians (2.7\%). Their qualifications differ; two (1.8\%) with masters degrees, 11 (10\%) with basic degrees, 94 (85.5\%) diplomas and three $(2.7 \%)$ with school certificates. The participants form four age groups. There were $50(45.5 \%)$ nurses aged between 20-30 years, followed by 46 (41.8\%) nurses aged between 31-40 years, then nine (8.2\%) nurses aged between $41-50$ years and lastly five $(4.5 \%)$ nurses aged between 51-60 years. The majority of the nurses 90 (81.8\%) in this study were married while 20 (18.2\%) were single. The majority of nurses, $51(46.4 \%)$ have a total of 1-3 children, $34(30.9 \%)$ have none, 19 (17.3\%) with 4-5 children and lastly six (5.5\%) of the nurses have more than five children.

When the nurses were categorised based on their BMI, most of the nurses 57 (51.8\%) were overweight, 47 (42.7\%) had normal BMI while six (5.5\%) were underweight. (Table 1) shows the association between employment profile of nurses and LBP. Results show that working experience in current ward and years of nursing experience were significantly associated with LBP. However, current working ward, working time, total hours of working per week and total patients who need mobilizing were not associated with LBP (Table 1). Table 2 shows the association between individual factors and occurrence of back pain. Crosstab Chi-square tests or tests of independence were carried out to determine individual factors related to LBP among nurses in CCUs. Age, marital status, total number of children, height, weight and BMI, smoking and regular exercise or sport were not significantly associated to LBP among nurses in CCUs (Table 2). After cross tabulation, Pearson ChiSquare test was used to determine the association between workrelated factors and occurrence of LBP. Only one factor, frequency standing had significant association with low back pain $(\mathrm{p}=0.021)$. However factors such as frequency of lifting patients in bed during shifts, helping patients to get out of the bed during shifts, poor body mechanics during lifting of patients, frequent carrying of heavy medical equipment during shifts, frequent moving of the beds during shifts, too much work to do, staff shortage in ward and stress were not significantly associated with low back pain among nurses (Table 3).
Table 1: Association between Employment Profile and LBP.

\begin{tabular}{|c|c|c|c|}
\hline Employment Profile & Had LBP n (\%) & No LBP n (\%) & $P$ value \\
\hline $\begin{array}{c}\text { Working Experience } \\
\text { (years) } \\
<1 \\
10-\mathrm{Jan} \\
20-\mathrm{Nov} \\
>20\end{array}$ & $\begin{array}{l}05(4.5) \\
30(27.3) \\
22(20.0) \\
36(32.7)\end{array}$ & $\begin{array}{l}02(1.8) \\
06(5.5) \\
08(7.3) \\
01(0.9)\end{array}$ & $0.038^{*}$ \\
\hline $\begin{array}{c}\text { Current Working } \\
\text { Ward } \\
\text { General medical } \\
\text { Cardiothoracic } \\
\text { CCU } \\
\text { HDU } \\
\text { ICU }\end{array}$ & $\begin{array}{l}10(9.1) \\
13(11.8) \\
15(13.6) \\
23(20.1) \\
32(29.1)\end{array}$ & $\begin{array}{l}03(2.7) \\
00(00.0) \\
05(4.5) \\
03(2.7) \\
06(5.4)\end{array}$ & 0.305 \\
\hline $\begin{array}{c}\text { Nursing Experience } \\
\text { (years) } \\
<1 \\
\text { 10-Jan } \\
20-\mathrm{Nov} \\
>20\end{array}$ & $\begin{array}{c}02(1.8) \\
27(24.5) \\
20(18.2) \\
44(40.0)\end{array}$ & $\begin{array}{c}00(00.0) \\
03(2.7) \\
11(10.0) \\
3(2.7)\end{array}$ & $0.004^{*}$ \\
\hline $\begin{array}{c}\text { Working Time } \\
\text { Day time only } \\
\text { Day and night time }\end{array}$ & $\begin{array}{l}22(20.0) \\
71(64.5)\end{array}$ & $\begin{array}{c}01(0.9) \\
16(14.5)\end{array}$ & 0.179 \\
\hline $\begin{array}{c}\text { Total Working } \\
\text { Hours Per Week } \\
\text { (hours) } \\
20-0 c t \\
21-30 \\
31-40 \\
>40 \\
\end{array}$ & $\begin{array}{c}02(1.8) \\
10(9.1) \\
24(21.8) \\
55(50.0)\end{array}$ & $\begin{array}{l}01(0.9) \\
02(1.8) \\
03(2.7) \\
13(11.8)\end{array}$ & 0.813 \\
\hline $\begin{array}{c}\text { Total Patients Need } \\
\text { Mobilizing } \\
0 \\
\text { 5-Jan } \\
\text { 10-Jun } \\
\text { 15-Nov }\end{array}$ & $\begin{array}{c}06(5.5) \\
52(47.3) \\
28(25.5) \\
07(6.4)\end{array}$ & $\begin{array}{c}00(00.0) \\
14(12.7) \\
02(1.8) \\
01(0.9)\end{array}$ & 0.232 \\
\hline
\end{tabular}

*Significant difference at $\mathrm{p}<0.05$

Table 2: Association between Individual Factors and LBP.

\begin{tabular}{|c|c|c|c|}
\hline $\begin{array}{c}\text { Individual } \\
\text { Factors }\end{array}$ & Had LBP n (\%) & No LBP n (\%) & p value \\
\hline Age (years) & $41(37.2)$ & $09(8.2)$ & \\
$20-30$ & $39(35.5)$ & $07(6.4)$ & 0.934 \\
$31-40$ & $08(7.3)$ & $01(0.9)$ & \\
$41-50$ & $05(4.5)$ & $00(00.0)$ & \\
$51-60$ & & & \\
\hline
\end{tabular}




\begin{tabular}{|c|c|c|c|}
\hline $\begin{array}{c}\text { Gender } \\
\text { Female } \\
\text { Male }\end{array}$ & $\begin{array}{l}71(64.5) \\
22(20.0)\end{array}$ & $\begin{array}{c}14(12.7) \\
03(2.7)\end{array}$ & 0.758 \\
\hline $\begin{array}{c}\text { Marital status } \\
\text { Married } \\
\text { Single }\end{array}$ & $\begin{array}{l}76(69.1) \\
17(15.5)\end{array}$ & $\begin{array}{c}14(12.7) \\
03(2.7)\end{array}$ & 1 \\
\hline 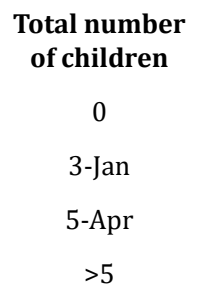 & $\begin{array}{c}31(28.2) \\
38(34.5) \\
18(16.4) \\
06(5.5)\end{array}$ & $\begin{array}{c}03(2.7) \\
13(11.8) \\
01(0.9) \\
00(00.0)\end{array}$ & 0.082 \\
\hline $\begin{array}{c}\text { Height(cm) } \\
141-150 \\
151-160 \\
161-170 \\
>171\end{array}$ & $\begin{array}{c}14(12.7) \\
53(48.2) \\
23(20.9) \\
03(2.7)\end{array}$ & $\begin{array}{l}03(2.7) \\
08(7.3) \\
05(4.5) \\
01(0.9)\end{array}$ & 0.274 \\
\hline $\begin{array}{c}\text { Weight (kg) } \\
\quad<50 \\
51-60 \\
61-70 \\
>71\end{array}$ & $\begin{array}{l}24(21.8) \\
30(27.3) \\
23(20.9) \\
16(14.5)\end{array}$ & $\begin{array}{l}04(3.6) \\
09(8.2) \\
03(2.7) \\
01(0.9)\end{array}$ & 0.148 \\
\hline $\begin{array}{c}\text { BMI } \\
\text { Underweight } \\
\text { Normal weight } \\
\text { Overweight }\end{array}$ & $\begin{array}{l}04(3.6) \\
38(34.5) \\
51(46.4)\end{array}$ & $\begin{array}{l}02(1.8) \\
09(8.2) \\
06(5.5)\end{array}$ & 0.221 \\
\hline $\begin{array}{c}\text { Smoking } \\
\text { Smoker } \\
\text { Non smoker }\end{array}$ & $\begin{array}{l}14(12.7) \\
79(71.8)\end{array}$ & $\begin{array}{c}03(2.7) \\
14(12.7)\end{array}$ & 0.786 \\
\hline $\begin{array}{c}\begin{array}{c}\text { Regular } \\
\text { exercise or } \\
\text { sport }\end{array} \\
\text { Yes } \\
\text { No }\end{array}$ & $\begin{array}{l}39(35.5) \\
54(49.1)\end{array}$ & $\begin{array}{c}03(2.7) \\
14(12.7)\end{array}$ & 0.058 \\
\hline
\end{tabular}

Table 3: Association between Work Related Factors and LBP.

\begin{tabular}{|c|c|c|c|}
\hline $\begin{array}{c}\text { Work related } \\
\text { factors }\end{array}$ & Had LBP n (\%) & No LBP n (\%) & P value $\boldsymbol{\chi 2}$ \\
\hline $\begin{array}{c}\text { Frequent lifting } \\
\text { patient } \\
\text { Yes } \\
\text { No }\end{array}$ & $\begin{array}{c}8(78.2) \\
7(6.4)\end{array}$ & $17(15.5) 0(0)$ & 0.242 \\
\hline $\begin{array}{c}\text { Helping patient } \\
\text { Yes }\end{array}$ & $88(80)$ & $17(15.5)$ & 0.328 \\
No & $5(4.5)$ & $0(0)$ & \\
\hline $\begin{array}{c}\text { Poor body } \\
\text { mechanics } \\
\text { Yes }\end{array}$ & $80(72.7)$ & $17(15.5)$ & 0.101 \\
\hline \multicolumn{2}{|c|}{} & $0(0)$ & \\
\hline
\end{tabular}

\begin{tabular}{|c|c|c|c|}
\hline No & $13(11.8)$ & & \\
\hline $\begin{array}{c}\text { Frequent carry } \\
\text { heavy medical } \\
\text { equipment } \\
\text { Yes } \\
\text { No }\end{array}$ & $\begin{array}{l}62(56.4) \\
31(28.2)\end{array}$ & $\begin{array}{c}12(10.9) \\
5(4.5)\end{array}$ & 0.751 \\
\hline $\begin{array}{l}\text { Frequent } \\
\text { moving the bed } \\
\text { Yes } \\
\text { No }\end{array}$ & $\begin{array}{l}80(72.7) \\
13(11.8)\end{array}$ & $\begin{array}{c}16(14.5) \\
1(0.9)\end{array}$ & 0.357 \\
\hline $\begin{array}{c}\text { Frequent } \\
\text { standing } \\
\text { Yes } \\
\text { No }\end{array}$ & $\begin{array}{l}70(63.6) \\
23(20.9)\end{array}$ & $\begin{array}{c}17(15.5) \\
0(0)\end{array}$ & $0.021^{*}$ \\
\hline $\begin{array}{c}\text { Too much work } \\
\text { Yes } \\
\text { No }\end{array}$ & $\begin{array}{l}68(61.8) \\
25(22.7)\end{array}$ & $\begin{array}{c}11(10.0) \\
6(5.5)\end{array}$ & 0.478 \\
\hline $\begin{array}{c}\text { Staff shortage } \\
\text { Yes } \\
\text { No }\end{array}$ & $\begin{array}{l}57(51.8) \\
36(32.7)\end{array}$ & $\begin{array}{c}10(9.1) \\
7(6.4)\end{array}$ & 0.848 \\
\hline $\begin{array}{c}\text { Stress } \\
\text { Yes } \\
\text { No }\end{array}$ & $\begin{array}{l}65(59.1) \\
28(25.5)\end{array}$ & $\begin{array}{c}10(9.1) \\
7(6.4)\end{array}$ & 0.368 \\
\hline
\end{tabular}

*Significant difference at $\mathrm{p}<0.0$.

\section{Discussion}

There was a significant difference in LBP between pre entering nursing and since entering nursing $(\mathrm{p}<0.001)$. This study demonstrates that the prevalence of LBP among the nurses studied increased from $16.4 \%$ pre nursing to $68.2 \%$ since entering nursing, which is rather close to studies done in western countries. Low back pain is a major problem in the nursing profession and it was reported that $30 \%$ and more nurses experienced low back pain during the nursing course of one year [6]. It was reported that only $15.9 \%$ nurses had LBP before nursing while $84.5 \%$ complained they had LBP after nursing [7]. There was a six percent increased risk of LBP from pre-nursing prevalence while the cumulative lifetime prevalence of LBP increased from $31 \%$ at entry to $72 \%$ at the end of nursing school [4]. Working experience at current ward and total years of nursing experience were related to LBP among nurses. The findings of this study show nurses with more than 20 years experience reported the highest LBP (32.7\%) whereas nurses working less than one year reported the least (4.5\%). Occupational back pain and level of seniority were positively related [8].

In another study on those with LBP, $59.5 \%$ had more than five years of nursing experience and another $12 \%$ had more than 20 years nursing experience [7]. Findings from this study indicate that the nurses working in Intensive Care Unit, ICU (29.1\%) and High Dependency Unit, HDU (20.1\%) were more likely to report current back pain compared to other units. In both ICU and HDU, most patients are usually dependent, frail and need more help from 
nurses for their daily activities and transfer compared to those in other wards [9]. Nurses who are working in ICU experienced an increased rate of LBP compared with other CCUs. Similar results were obtained in 65 ICU in 22 South Korean hospitals and among 1345 subjects where $90.3 \%$ had back pain [10]. In addition, Nurses with 2-4 years of working experiences in ICU had the greatest probability of back pain and needed treatment. Although most hospitals allow patient's family to stay in the ward help to take care of the patient, the availability of family members to do this caring in hospital was low in busy city [9]. Report had shown a 65\% lifetime and $70 \%$ point prevalence for low back pain among nurses working in the orthopaedic unit as well as 58\% lifetime and 75\% point prevalence of low back pain for those working in the intensive care unit [5]. More nurses with more than 20 years nursing experience including year three student nurses had LBP (40\%) compared to nurses with 1-10 years working experience (24.5\%). In another study, $12 \%$ of nurses with more than 20 years working experience suffered LBP [7].

This study found most nurses working shift had LBP (64.5\%). Comparing the back pain prevalence across AM, PM and nightshifts, the staff working on AM shift are more likely to experience back pain $(28.3 \%)$. However there was a higher prevalence of back pain during the night shift (6.6\%) compared to the PM shift (1.5\%) [8]. There was a $64 \%$ increase in LBP among those who reported staff shortage and working six or more night shifts per month [10]. Nurses working on the AM shift were more likely to experience back pain. Most of patients' hygiene needs such as bed sponging, assisted baths and treatment procedures are carried out during the AM shift, which involves a lot of patient lifting and transferring. Nurses with total working hours between 31-40 hours per week had higher occurrence of LBP (21.8\%) while those working between 10-20 hours per week had less LBP (1.8\%). Nurses working more than 50 hours per week had the most LBP (50.0\%). Study had shown that nurses working more than 20 hours per week had symptoms of LBP [11]. Nurses who were handling and mobilizing between 1-5 patients per shift had the most LBP $(47.3 \%)$ while those without such patients the least (5.5\%). Study had reported LBP among $58.4 \%$ of nurses handling and mobilizing between 1-5 patients but only $6.7 \%$ among nurses who did not have to [7].

Younger nurses aged between 20-30 years (37.3\%) had the highest LBP while older nurses aged between 51-60 years had least LBP (4.5\%). Studies had shown that nurses between the ages of 20 to 30 years had the highest prevalence of occupational back pain $[8,12,13]$. Junior nurses had higher rate of back pain because they were more involved in manual work, while the senior staffs were assuming more of organisational and managerial roles. Junior nurses were also less knowledgeable in the proper techniques of lifting and body mechanics. Senior nurses could have developed effective coping strategies over time. Younger nurses also had more problems related to job stress than older nurses [8]. Another study showed that nurses aged 50-59 years were most affected by LBP [14]. However, there is the healthy worker effect, that is those who suffers from LBP tend to leave their hospital jobs, whereas the healthy nurses stay $[1,9]$. Female nurses tend to experience more back pain $[1,7,12,15-18]$. Results of this study showed that $64.5 \%$ of female nurses and $20 \%$ of male nurses had LBP. More married women had LBP compared to unmarried women. The finding of this study indicated that $69.1 \%$ married women had LBP in their lifetime. Various studies reported that more married women had LBP. As high as $85.8 \%$ women who were married had LBP [4]. LBP are more common among nurses with multiple pregnancies. Our study found that $34.5 \%$ nurses with 1-3 children have LBP.

This is similar to the report that $51.5 \%$ nurses with multiple pregnancies experienced LBP [4]. Female participants reported that their back pain was attributed to pregnancy and childbirth [19]. Obesity, which is one of the contributing factors for lumbar pain, leads to decreased abdominal muscle strength and increases the level of lumbar-lordosis. This is supported by this study where $46.4 \%$ of those who were overweight had LBP. Studies showed that lifting, prior injury, and being overweight were risk factors for workrelated low back injury (WLBI) among nurses [5]. Age, increased BMI and disturbed psychological profile were among other individual factors shown to be related to increased risk of WLBI [4]. Smoking was cited in the literature as having a negative effect on the circulatory system. Cigarette nicotine causes vasoconstriction that reduces the blood flow to the muscles and intervertebral discs. This predisposes smokers to low back injuries [5]. Increased coughing among smokers may be related to increased risk of low back injuries in this group [4]. There was a strong relationship between smoking more than 20 cigarettes a day and having back pain and intervertebral disc degeneration. Study done in Japan indicated that smoking was associated with LBP [7].

There was no significant relationship between smoking and back pain in this study, only $12.7 \%$ of the nurses smoked and had LBP while $71.8 \%$ had LBP but did not smoke. Smoking can cause other illnesses related to smoking in addition to back pain [20]. A smaller percentage of the nurses who exercised regularly (35.5\%) had LBP compared to $49.1 \%$ of nurses who did not exercise regularly. Although there was no significant relationship between exercise and back pain, the group of people who did not exercise regularly are at a greater risk for back pain. However exercise or sports did not play a protective role against LBP [7]. Several factors can cloud these results namely, the level of competition, nature of sports activities as well as the volume and the intensity of the exercises. In this study professional factors chosen by nurses as causes of LBP were frequent lifting of patients in one shift (78.2\%), helping patient to ambulated (80.0\%), poor body mechanics $(72.2 \%)$, frequency of moving the bed $(72.2 \%)$, frequent standing $(63.6 \%)$, too much work (61.8\%), shortage of staff (51.8\%), and stress $(86.7 \%)$. The nursing job is more to helping, turning and lifting the patient from chair or bed [9]. This study shows that $78.2 \%$ nurses who did frequent lifting and $80 \%$ nurses who helped patients had LBP.

Considering that nurses often work 12 hour-shifts, the amount of lifting adds up and the job could be very hard to manage physically [5]. Some studies suggest that positioning patients in bed leads to LBP more often than other manual patient transfer procedures conducted by nurses $[21,22]$. Nurses who handled patients more 
frequently have low back pain prevalence rates that were 3.7 times higher [23]. Among nurses who had LBP, 72.7\% chose poor body mechanics as the factor. According to National Institute of Occupational Safety and Health (NIOSH) lifting guidelines, the maximum recommended weight to be lifted by women in the 90th percentile of strength is $46 \mathrm{lbs}$. Nurses were commonly led to believe that the primary way to prevent back injuries was to always use proper body mechanics. However, the fact remains that some tasks were so stressful to the body that even with proper body mechanics, a back injury resulted [22]. Rooms in hospital are often small, and nurses had to move the furniture around so that they can do their jobs. Most of the time nurses are lifting devices that would not even fit in these rooms; these are some causes of LBP [5]. Some patients may also be combative, contracted, or uncooperative. Any unpredictable movement or resistance from the patient may throw the nursing personnel off balance during the transfer, resulting in back injury [5].

In addition, fatigued muscles can no longer serve their protective function and may add to the risk of acute trauma [22]. Workplace guidelines should limit manual handling exposure in general or enable nurses to undertake reduced manual handling activities when in pain [12]. Shortage of staff is also one of the factors contributing to LBP. This study indicated that $51.8 \%$ nurses who suffered LBP chose staff shortage in wards as the factor. Surprisingly, low work support, low mood, and boring work tasks were not identified as MSD risk factors in this study. In this study $59.1 \%$ of nurses who complaint of stress had LBP while only $25.5 \%$ of those who did not complaint of stress had LBP. This is supported by study where $57.3 \%$ of stressed nurses suffered from LBP [7]. As such, these results suggest that psychosocial issues are fast becoming increasingly important MSD risk factors for nurses in Asia as elsewhere.

\section{Conclusion}

The results of this study demonstrated that the prevalence of low back pain among nurses at HUSM was only $16.4 \%$ before entering nursing but $68.2 \%$ upon entering nursing. The difference in LBP between pre nursing and since nursing was significant $(\mathrm{p}=0.001)$. Furthermore, nursing employment profile such as working experience in current ward $(\mathrm{p}=0.004)$ and nursing experience ( $p=0.038$ ) were significantly related to LBP. Current working ward, working time, total working hours per week and total patient need mobilizing were not associated with LBP. None of the individual factors studied were significantly associated with LBP among the nurses. As for the work related factors, frequency standing during shift was found to be associated with LBP ( $p=0.021)$ while other factors were not significantly associated with occurrence of LBP.

\section{References}

1. Branney J, Newell D (2009) Back pain and associated healthcare seeking behaviour in nurses: A survey. Clinical Chiropractic 12(4): 130-143.

2. Mitchell T, O Sullivan PB, Burnett AF, Straker L, Rudd C (2008) Low back pain characteristics from undergraduate student to working nurse in Australia: A cross-sectional survey. International Journal of Nursing Studies 45(11): 1636-1644.
3. Menzel NN, Brooks SM, Bernard TE, Nelson A (2004) The physical work worload of nursing personnel: association with musculoskeletal discomfort. International Journal of Nursing Studies 41(8): 859-867.

4. Bejia I, Younes M, Jamila HB, Khalfallah T, Ben Salem K, et al. (2004) Prevalence and factors associated to low back pain among hospital staff. Joint Bone Spine 72(3): 254-259.

5. Vieira ER, Kumar S, Coury HJCG, Narayan Y (2006) Low back problems and possible improvements in nursing jobs. Journal of Advanced Nursing 55(1): 79-89.

6. Mitchell T, O'Sullivan PB, Burnett AF, Straker L, Rudd C (2008) Low back pain characteristics from undergraduate student to working nurse in Australia: A cross-sectional survey. International Journal of Nursing Studies 45(11): 1636-1644.

7. Wong TS, Teo N, Kyaw MO (2010) Prevalence and risk factors associated with low back pain among health care providers in Distirict Hospital. Malaysian Orthopedic Journal 4(2): 23-29.

8. Chen XR (2008) Occupational Back Pain Among Hospital Nurses. Journal of Advanced Nursing 17(2): 79-87.

9. Yip Y (2001) study of work stress, patient handling activities and the risk of low back pain among nurse in Hong Kong. Journal of Advanced Nursing 36(6): 798-804.

10. Kyung JJ, Cho SH (2011) Low back pain and work-related factors among nurses in intensive Care Units. Journal of Clinical Nursing 20(3-4): 479487.

11. Horneij E, Hemborg B, Johnsson B, Ekdahl C (2002) Clinical tests on impairment level related to low back: A study of test reliability. Journal of Rehabilitation Medical 34(4): 176-182.

12. Dawson AP, Schluter PJ, Hodges PW, Stewart S, Turner C (2011) Fear of movement, passive coping, manual handling, and severe or radiating pain increase the likelihood of sick leave due to low back pain. PAIN 152(7): 1517-1524.

13. Roupa Z, Vassilopoulos A, Sotiropoulou P, Makrinika E, Noula M, et al. (2008) The problem of lower back pain in nursing staff and its effect on the human activity. Journal of Health Science 3(4): 219-225.

14. Hamid SN, Ali Akbar H, Zahra B, Mohammad Ali S, Nasim B, et al. (2011) Relationship between backache and psychological and psychosocial job factors among the nurses. International Journal of Nursing and Midwifery 3(7): 86-91.

15. Louw QA, Morris LD, Grimmer-Somers K (2007) The Prevalence of low back pain in Africa: a systematic review. Occupational and environmental medicine 8: 105-110.

16. Mendelek F, Kheir RB, Caby I, Thevenon A, Pelayo P (2011) On the quantitative relationships between individual/occupational risk factors and low back pain prevalence using nonparametric approaches. Joint Bone Spine 78(6): 619-624.

17. Otani T, Iwasaki M, Ohta A, Kuroiwa M, Yosiaki S, et al. (2002) Low back pain and smoking in a community sample in Japan. Journal of Occupational Health 44(4): 207-213.

18. Szeto GPY, Ho P, Ting ACW, Poon JTC, Cheng SWK, et al. (2009) Workrelated musculoskeletal symptoms in Surgeon. Journal of Occupational Rehabilitation 19(2): 175-184.

19. Campbell C, Muncer SJ (2005) The causes of low back pain: a network analysis. Social Science Medicine 60(2): 409-419.

20. Karahan A, Kav S, Abbasoglu A, Dogan N (2009) Low back pain: Prevelence and associated risk factors among hospital staff. Journal of Advanced Nursing 65(2): 516-524.

21. Dosoglu M, Yldz U, Is M, Orhan Z (2009) Low back pain among nurses: a review. Neurosurgery Quarterly 19(1): 29.

22. Edlich RF, Winters KL, Hudson MA, Britt LD, Long WB (2004) Prevention of disabling back injuries in nurses by the use of mechanical patient lift 
systems. Journal of Long-Term Eff ects of Medical Implants 14(6): 521533.
23. De Castro AB, Cabrera SL, Gee GC, Fujishiro K, Tagalog EA (2009) Occupational Health and Safety Issues Among Nurses in the Philippines. AAOHN Journal 57(4): 149-157.

$\begin{array}{ll}\text { BIOMEDICAL } & \text { Assets of Publishing with us } \\ \text { RESEARCHES } & \text { - Global archiving of articles } \\ & \text { - Immediate, unrestricted online access } \\ & \text { - Rigorous Peer Review Process } \\ & \text { - Authors Retain Copyrights }\end{array}$

